\title{
The sensitivity of ocean-bottom gravimeters at deep waters to mass changes in a synthetic hydrocarbon reservoir
}

\author{
André D. Arelaro*1,2, Valéria C. F. Barbosa ${ }^{1}$, Vanderlei C. Oliveira Junior ${ }^{1}$.
}

${ }^{1}$ Observatório Nacional, ${ }^{2}$ Petrobras.

Copyright 2019, SBGf - Sociedade Brasileira de Geofísica

This paper was prepared for presentation during the $16^{\text {th }}$ International Congress of the Brazilian Geophysical Society held in Rio de Janeiro, Brazil, 19-22 August 2019.

Contents of this paper were reviewed by the Technical Committee of the $16^{\text {th }}$ International Congress of the Brazilian Geophysical Society and do not necessarily represent any position of the SBGf, its officers or members. Electronic reproduction or represent any position of the SBGf, its officers or members. Electronic reproduction of storage of any part of this paper for commercial
the Brazilian Geophysical Society is prohibited.

\begin{abstract}
This paper presents a preliminary feasibility study of ocean-bottom 4D gravimetry survey focused on oil production monitoring. We have conducted numerical simulations by computing the vertical component of the gravitational attraction exerted by a synthetic petroleum reservoir. Three parameters were tested regarded a detectability limit of $3 \mu \mathrm{Gal}$ : oceanic tides, reservoir depth and reservoir density changes simulating oil production. For this value, tides with a magnitude of few centimeters can affect the data, even at great distances from the measurement points. A $25 \mathrm{~m}$ thick reservoir could be detected even at $7 \mathrm{~km}$ depth. Differences in density could be detected after $20 \%$ of oil to salt water substitution in a reservoir at $3 \mathrm{~km}$ depth.
\end{abstract}

\section{Introduction}

In oil industry, the search for exploratory opportunities are becoming increasingly deep, concerning seawater thickness and overburden thickness. This fact brings an additional challenge to geophysical imaging, including the gravimetric method, which is sensitive to lateral density variations. When the distance between geological sources and gravity acquisition sensors increases, data loses resolution at the rate of the square of the distance. For very large distances, the data acquisition does not appropriately image the geological features of interest. Conventional marine gravimetry, carried on by ships, is broadly affected by this problem. One way to reduce this undesired effect in marine regions is to take the sensors to the ocean bottom surface.

Sea-bottom 4D gravity measurements, the focus of this study, have been made since the 1940's (PEPPER, 1941) in shallow waters (about $1000 \mathrm{~m}$ deep) and since the 2000's this technique is used for subsidence and oil production monitoring in North Sea (STENVOLD (2008), AGERSBORG et al. (2017)). In deeper waters, as in Brazilian offshore for instance, this type of acquisition can become a technological challenge. Hence, it is important to understand the parameters that control the feasibility of a 4D gravimetric sea bottom acquisition in deep and ultradeep waters.
In a simple way, 4D or time-lapse acquisitions are the repetition of two or more $3 \mathrm{D}$ acquisitions in different periods. The first acquisition is called base acquisition, once the further acquisitions - called monitor acquisitions - always are referred on this first acquisition. The acquisitions are designed in a way that the sensors were set approximately in the same spatial position for all of them, that is, the repeatability be high. The difference between the monitor and the base acquisition results in a 4D signal. In gravimetry this 4D signal represents the difference in geometry and/or physical properties (density) during the period of the acquisitions. The objective of a 4D gravity acquisition is to identify, quantify and separate these time-variable effects, generating a dynamical interpretation of the study area. It is crucial that these effects are above the instrumental noise level.

In oil industry 4D gravimetry can help to understand the mass balance during the production of an hydrocarbon reservoir due to the substitution of this hydrocarbon by (commonly) water or $\mathrm{CO}_{2}$, which is a very challenging and important estimation in reservoir monitoring (STENVOLD (2008), VAN CAMP et al. (2017)). As could be expected, marine 4D gravity acquisition is much more complex than its equivalent acquisition in land. It becomes even more complex when the sensors are in the sea-bottom. Nowadays sea-bottom 4D gravity measurements need a ship from where concrete benchmarks and the sensors are positioned in the sea-bottom. Concrete benchmarks define the positions of the stations in the seafloor and helps to improve the repeatability of the surveys. The sensors are devices compound by three relative gravimeters and three pressure gauges. Both benchmarks and sensors are set in the sea-bottom by a ROV (remotely operated vehicle) (AGERSBORG et al. (2017)). The sensor stays 20 minutes performing measurements in each station to lower the error related to the transportation of the device (VAN CAMP et al. (2017)). An acquisition can last some days or weeks, depending on the number of the stations (AGERSBORG et al. (2017)).

Focusing on oil production monitoring, we stress that a good reservoir monitoring can bring positive indicators in two critical factors for an oil company: increase of oil recovery factor and improvement of the security in the production facilities. For example, an increase of $1 \%$ in oil recovery can generate an exceeding oil production whose profits can surpasses hundreds of times the cost of the sea-bottom 4D gravity acquisition. Additionally, this type of acquisition can provide useful information about reservoir expanding and compaction, which helps in sea bottom monitoring for preservation of the integrity of submarine installations. Finally, 4D gravity acquisition also helps in reduce the uncertainty of the prediction of the drainage in 
the reservoir, a key factor in the choice of the position of infill wells (ROSTE \& KE (2017)). Therefore, the incorporation of a trustful methodology of sea-bottom 4D gravity acquisition can be very advantageous for the oil companies that have marine hydrocarbon fields in their portfolios.

Because of this reasons, this paper intends a better comprehension of three parameters used in a sea-bottom 4D gravity survey: oceanic tides, depth of the source and variation of density due to fluid substitution in a simulated reservoir. We have simulated a 4D gravity survey for analyzing which scenarios can be detected concerning a given uncertainty value. The codes are in Python programming language and some functions were used from open-source Python packages called Fatiando a Terra (UIEDA et al., 2013).

The synthetic applications of this study simulate an oil production monitoring, where ocean-bottom 4D gravimetry survey can help to identify the fluid movement inside the reservoir, indicating regions where the hydrocarbons were not exploited yet.

Initially, tests were done regarding the detectability of the ocean tides changing in space and time given a certain bathymetry. In 4D marine gravimetry, it is important to understand the undesired effect caused by tides in the data, in order to separate it from the desired signal that comes from the reservoir. Results showed that for a limit of detectability of $3 \mu \mathrm{Gal}$ (related to the uncertainty of a measurement in a single station - see section Method for further details) tides of few centimeters can affect the data and this is independent of the distance between sensor (gravimeter) and the source (tides). After that, a simple reservoir model was used to test the detectability regarding its depth and the density changes due to a simulated fluid substitution. We can see, for the same limit of detectability, that it is possible to detect a 4D signal when the reservoir is at $3000 \mathrm{~m}$ and the percentage of oil to salt water substitution is between $10 \%$ and $20 \%$.

\section{Method}

The synthetic data was generated through gravity modelling, where each model was divided in rectangular $3 D$ prisms. Then, the vertical component $g_{z}$ of the gravitational acceleration of the prisms was calculated. The formula of the $g_{z}$ in a point $P$ generated by a prism with limits in $x_{1}, x_{2}, y_{1}, y_{2}, z_{1}, z_{2}$ and density $\rho$, is given by BLAKELY (1995):

$$
\begin{aligned}
g_{z}(P)=\gamma \rho \sum_{i=1}^{2} \sum_{j=1}^{2} & \sum_{k=1}^{2} \mu_{i j k}\left[x_{i} \ln \left(y_{j}+r\right)+y_{j} \ln \left(x_{i}+r\right)\right. \\
& \left.-z_{k} \tan ^{-1}\left(\frac{x_{i} y_{j}}{z_{k} r}\right)\right]
\end{aligned}
$$

where $\mu_{i j k}=(-1)^{i}(-1)^{j}(-1)^{k}$ and $r$ is the distance from the prism to the point $P$.

Two models were made in this work. The first one simulates a bathymetry of an offshore Brazilian region and an overlain seawater layer. The top of the seawater layer varies in space $(x, y)$ and time $(t)$ according to the following equation:

$f(x, y, t)=\frac{A}{2}\left[\cos \left(\frac{2 \pi}{L_{x}} x+\frac{2 \pi}{T} t\right)+\cos \left(\frac{2 \pi}{L_{y}} y+\frac{2 \pi}{T} t\right)\right]$

where $A$ is the amplitude, $L_{x}$ and $L_{y}$ the size of the model in $x$ and $y$ respectively. In this case, both have $23 \mathrm{~km}$ long. $T$ is the period of the function, with value $7500 \mathrm{~s}$. Figure 1 gives an example of this function in a certain time. The gravitational effect were calculated regarding several amplitudes (variable A in equation 2) in order to evaluate the limit of detectability of $3 \mu \mathrm{Gal}$. This value was chosen after in-situ analysis of calibration parameters in two 4D gravimetric sea-bottom surveys, in Mikkel and Ormen Lange hydrocarbon fields, North Sea. The complete proceeding is described in AGERSBORG et al. (2017).

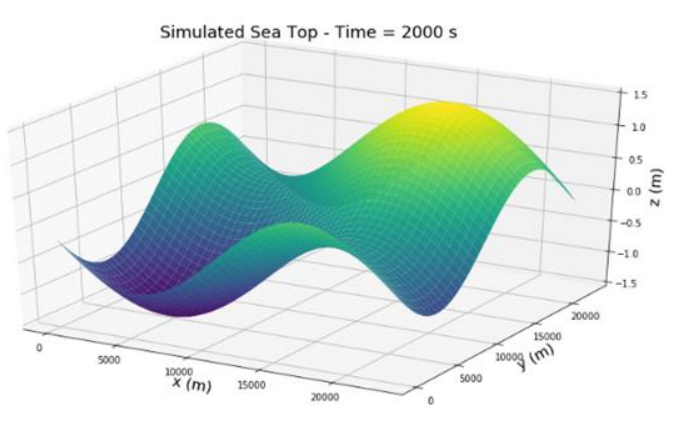

Figure 1 - Representation of the top of the seawater layer at $\mathrm{t}=2000 \mathrm{~s}$ given by (equation 2 ).

The second model has $15 \mathrm{~km}$ in north-south direction, 10 $\mathrm{km}$ in east-west direction and $8 \mathrm{~km}$ in the $z$ direction, with $2500 \mathrm{~kg} / \mathrm{m}^{3}$ density. Inside it there is a rectangular prism representing a reservoir with dimensions $8 \mathrm{~km}$ by $3 \mathrm{~km}$ by $25 \mathrm{~m}$, as can be seen in Figure 2. Initially, the depth of the reservoir (with a constant density) was changed and the gravitational effect calculated. Then the reservoir was fixed in a certain depth and its density was changed simulating a fluid substitution, according to the following equation (SCHLUMBERGER, 1989):

$\rho_{b}=\phi\left[\alpha \rho_{f}+(1-\alpha) \rho_{o}\right]+(1-\phi) \rho_{r}$

where $\rho_{b}$ is the density bulk of the reservoir, $\phi$ is the porosity, $\alpha$ is the percentage of change of fluid, and $\rho_{f}, \rho_{o}$ and $\rho_{r}$ are the densities of the fluid, the oil and the rock, respectively. The results of the several scenarios tested with this model were also evaluated concerning the same uncertainty value of $3 \mu \mathrm{Gal}$.

\section{Results}

We used equations 1 and 2 to calculate the gravitational effect produced by the seawater layer model through time, with the average sea level as reference. A comparison between sea surface and its gravitational effect is shown in Figure 3. It is possible to see the inverse correlation between the sea surface and gravity value. This means that the where the water reaches its maximum above sea level, it generates the more intense lows in gravity data. It occurs because there is more mass of water pulling up the hypothetical gravimeter in the surface direction, 
remembering the gravimeter is placed at the sea-bottom. The relationship between lows in seawater surface and highs in gravity effect follows the same idea.

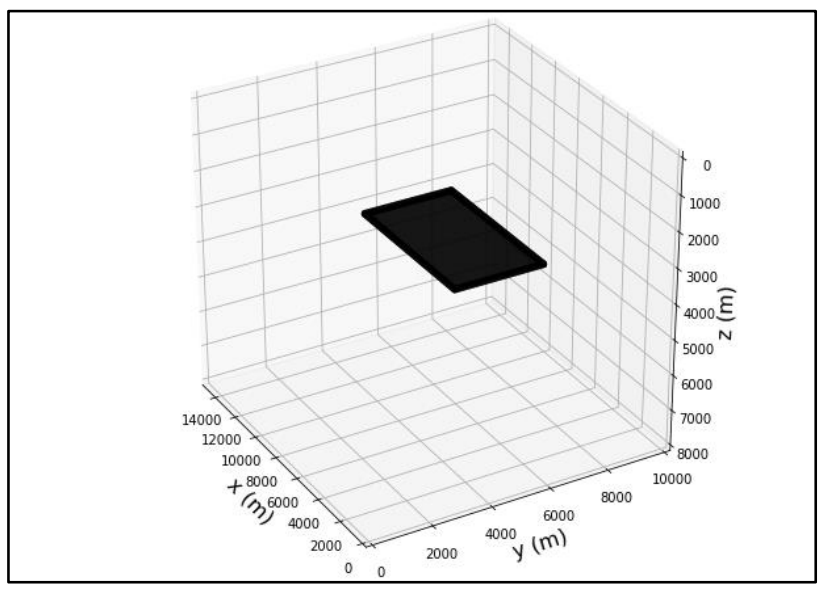

Figure $2-3 D$ model representing a reservoir. Its depth and density were changed in several scenarios as described later in the section Results.

In Figure 3 (left panel) it is also possible to see that an amplitude (variable $A$ in equation 2) of about $1.5 \mathrm{~m}$ generates a $0.03 \mathrm{mGal}$ effect, that is one order of magnitude greater than the uncertainty $(0.003 \mathrm{mGal}$ or 3 $\mu \mathrm{Gal})$. Figure 4 shows gravitational effect as a function of the amplitude (variable $\mathrm{A}$ in equation 2) and considering a gravity station at $1744.58 \mathrm{~m}$ deep, where we can see the uncertainty value is achieved at amplitudes of about $7 \mathrm{~cm}$. It means that for this depth, tides greater than $7 \mathrm{~cm}$ affect the data because they generate gravitational effect above the detectability limit.

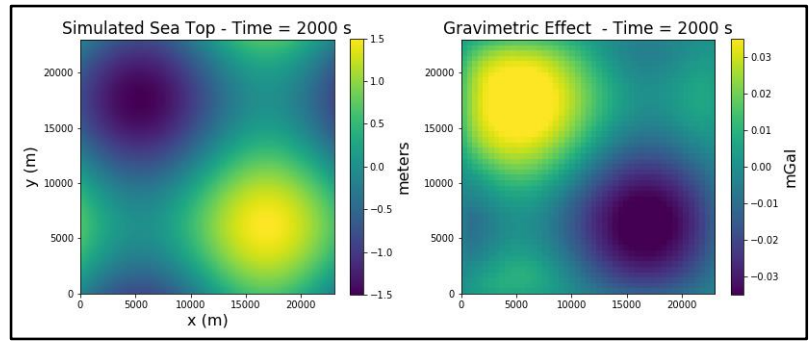

Figure 3 - Comparison between top of the seawater layer generated by equation (2) (left panel) and its gravitational effect generated by equation (1) (right panel) at $t=2000 \mathrm{~s}$. The amplitude (variable A used here) is $1.5 \mathrm{~m}$.

Figure 5 shows this same result but for several depths of gravity stations. It's important to note that the sea bottom depth does not play a big role regarding the uncertainty limit. It can be explained by the fact that the amplitude range of the tide (centimeter-scale), is very small compared with the large-scale model (kilometer-scale). If the model were infinite, the seawater layer could be considered as a Bouguer plate, where the distance between the measurement point and the plate does not significantly affect the calculation of its gravitational effect, only the thickness of the plate. If it were so, curves representing the depth of the measurement in Figure 5 would be equal.

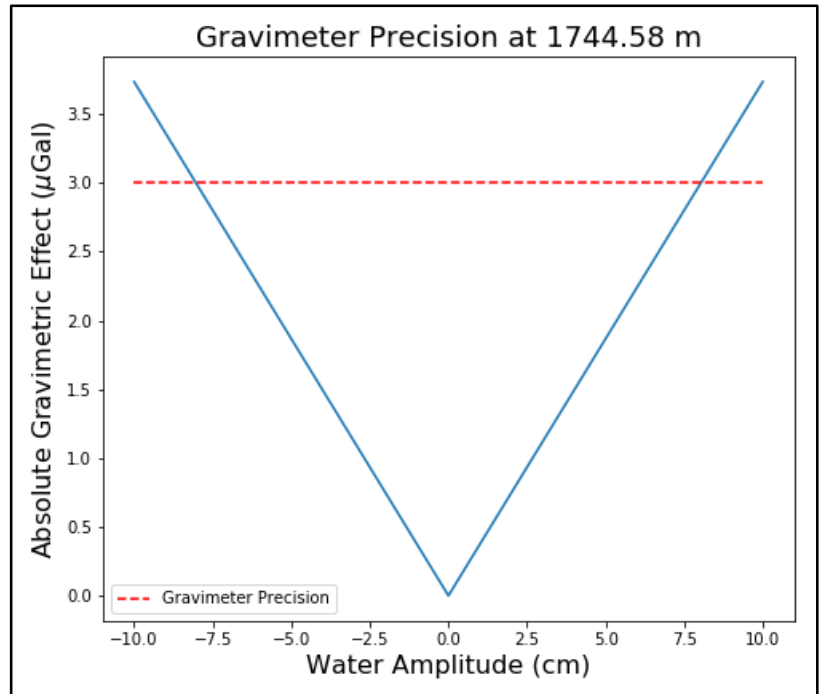

Figure 4-Gravitational effect as a function of seawater amplitude (variable $A$ in equation 2) and considering a gravity station at $1744.58 \mathrm{~m}$ deep. The dotted red line represents the uncertainty on gravity measurement of 3 $\mu \mathrm{Gal}$. Amplitudes under this uncertainty occurs where the blue line is under the red line.

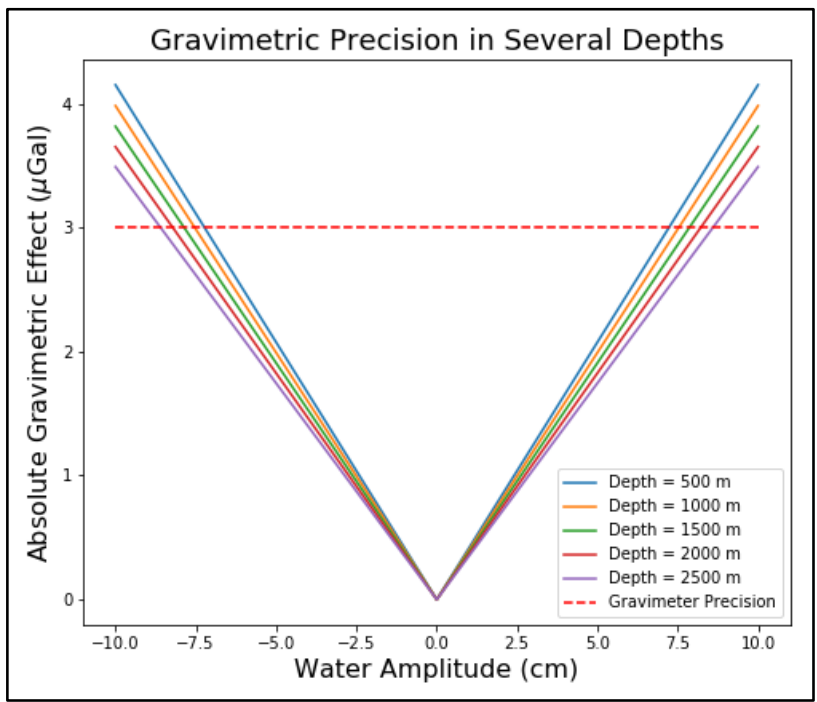

Figure 5 - Gravitational effect as a function of seawater amplitude for several depths. The dotted red line represents the uncertainty on gravity measurement of 3 $\mu$ Gal. Amplitudes under this uncertainty occurs where the solids lines are under the red line.

Regarding to the simple reservoir model (Figure 2), its initial bulk density represents the moment before the production starts, which means $\alpha=0$ in equation (3). We set $20 \%$ for $\phi, 1060 \mathrm{~kg} / \mathrm{m}^{3}$ for $\rho_{\mathrm{f}}$ (very salt water), $850 \mathrm{~kg} / 3$ for $\rho_{0}$ (oil) and $2350 \mathrm{~kg} / \mathrm{m}^{3}$ for $\rho_{\text {r }}$ (sandstone) resulting in a bulk density of $2050 \mathrm{~kg} / \mathrm{m}^{3}$, a contrast of $-450 \mathrm{~kg} / \mathrm{m}^{3}$ with the density background $\left(2500 \mathrm{~kg} / \mathrm{m}^{3}\right)$. The gravitational effect when the reservoir is at $3000 \mathrm{~m}$ deep can be seen in Figure 6 . In all tests, we assume a flat sea bottom depth of $1800 \mathrm{~m}$. 


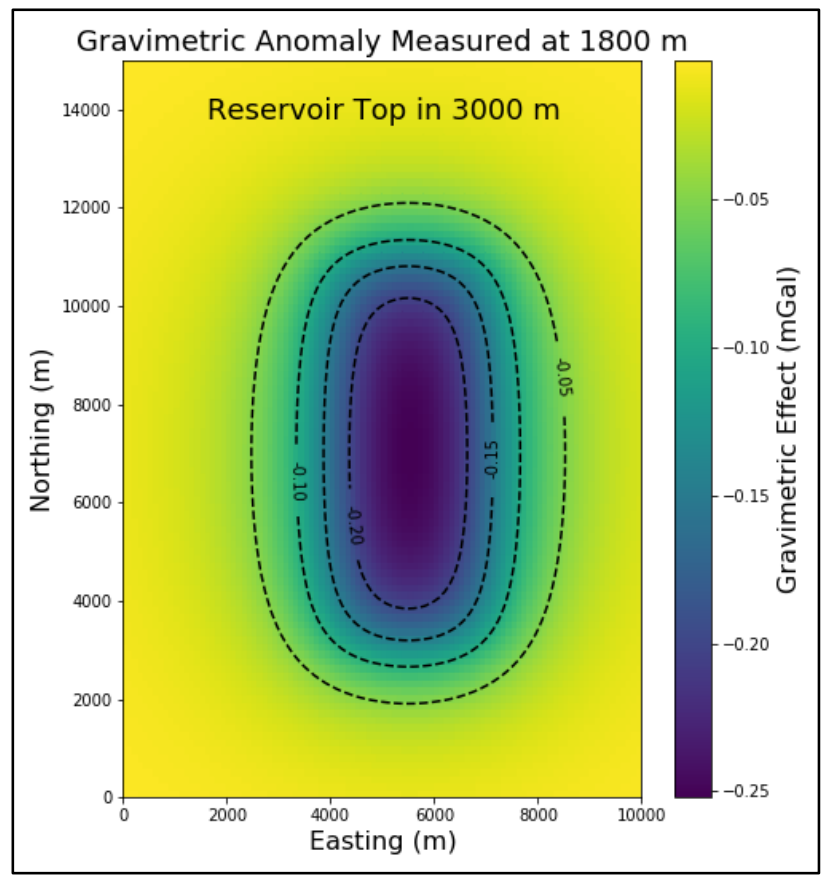

Figure 6 - Gravitational effect of the reservoir shown in Figure 2 . Its density contrast with the background is -450 $\mathrm{kg} / \mathrm{m}^{3}$.

When the reservoir becomes deeper, its gravity effect tends to reduce. To illustrate this behavior, Figure 7 shows the gravitational effect of the reservoir for different depths. Note that even when the top of the reservoir is at $7 \mathrm{~km}$ deep, which means a very deep reservoir in real cases, the gravitational signal is above the uncertainty limit of 0.003 $\mathrm{mGal}$ or $3 \mu \mathrm{Gal}$. Hence, a sea-bottom gravimeter at 1800 $\mathrm{m}$ deep can detect a reservoir at $7 \mathrm{~km}$ deep, with volume of about $6 \mathrm{~km}^{3}$.

As already seen, equation 3 establishes the density bulk of a reservoir considering a fixed time of its production and a given percentage of fluid substitution. Figure 6 shows the gravitational effect generated by the reservoir of the Figure 2 before its production starts. In this case, the percentage of fluid substitution (variable $\alpha$ in equation 3 ) is null. When the production in the reservoir starts, the percentage of fluid substitution increases and thus the gravity effect tends to lose its amplitude, because the density contrast diminishes. To illustrate this behavior, Figure 8 shows the 4D gravity effects for increasing percentages of fluid substitution in the reservoir at $3 \mathrm{~km}$ deep (Figure 6). The amplitude of the effect is caused by the difference between the moment before production ( $\alpha$ null) and the respective values of alpha. We can see that the gravitational effect due to reservoir production is greater than the uncertainty of $3 \mu \mathrm{Gal}$ (dashed red lines) when the percentage of fluid substitution is between $10 \%(\alpha=0.10)$ and $20 \%(\alpha=020)$. Moreover, large percentages of fluid substitution (up to $30 \%$ ) yield a gravitational signal above the uncertainty for almost all the reservoir area. Hence, a sea bottom gravimeters at $1800 \mathrm{~m}$ deep can detect a reservoir at $3 \mathrm{~km}$ deep with volume of about $6 \mathrm{~km}^{3}$ and with a percentage of fluid substitution up to $30 \%$.

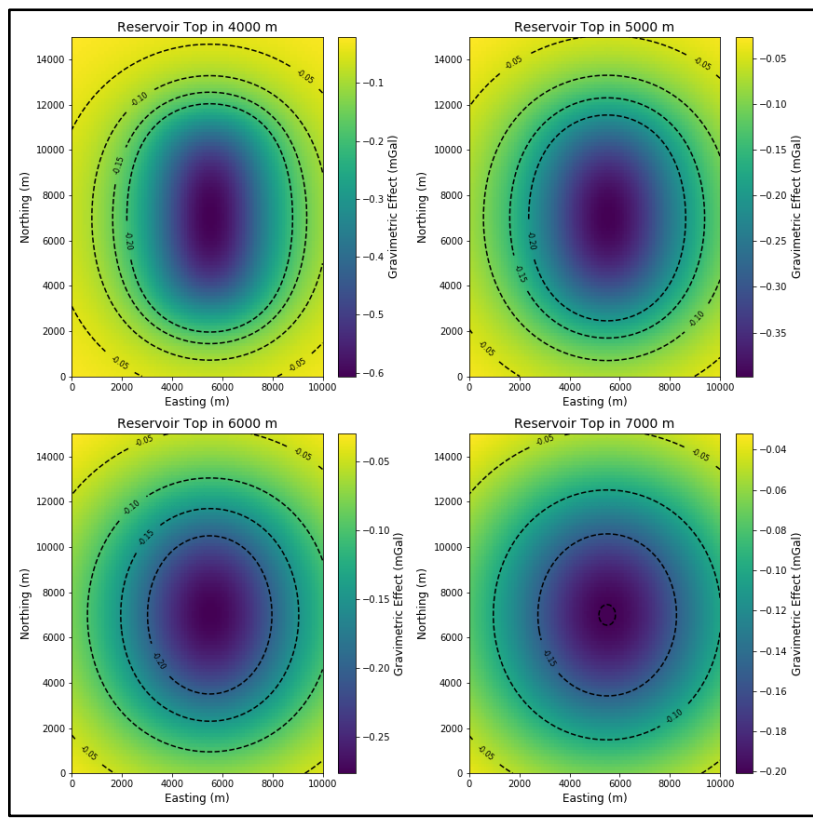

Figure 7 - Gravitational effects produced by reservoirs whose tops are located between $4 \mathrm{~km}$ and $7 \mathrm{~km}$ deep. The density contrast of the reservoir with the background is $450 \mathrm{~kg} / \mathrm{m}^{3}$.

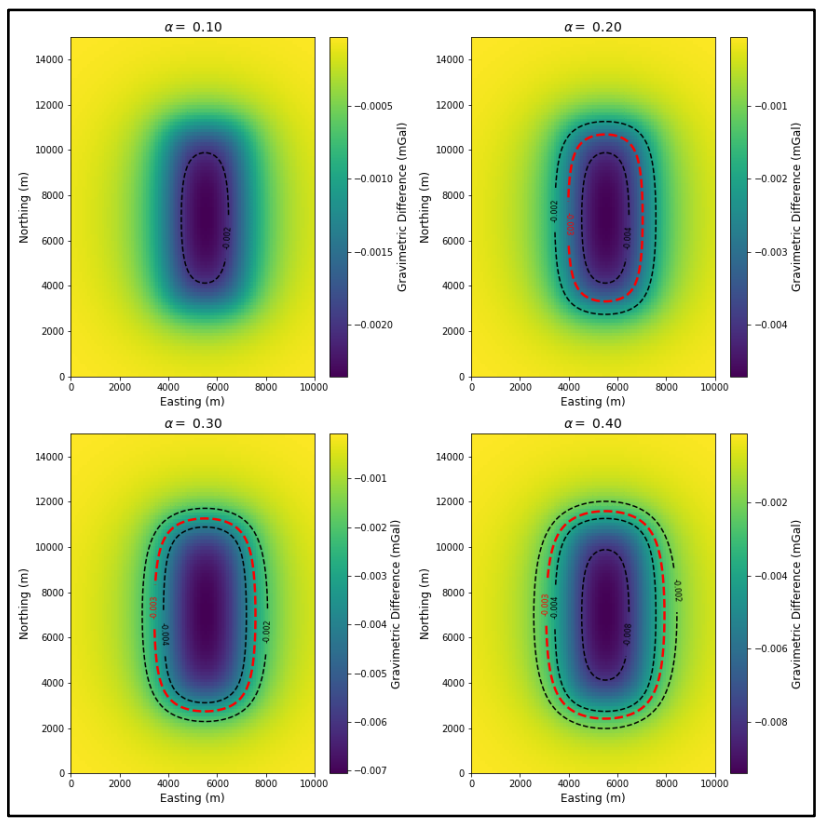

Figure 8-4D gravitational effect of the reservoir model in Figure 6 for several values of percentage of fluid substitution (variable $\alpha$ in equation 3 ). The amplitude of the effect is the difference between the moment before production ( $\alpha$ null) and the respective values of alpha. The dotted red line represents gravitational the uncertainty of the measurement $(3 \mu \mathrm{Gal})$.

\section{Conclusions}

We studied the sensitivity of sea-bottom gravimeters at deep waters to supervise mass changes in a simulated 
reservoir due to fluid substitution. We also studied the effect generated by tides changing in space and time. The limiting amplitude of the tides concerning the uncertainty value of $3 \mu \mathrm{Gal}$ is about $7 \mathrm{~cm}$, and this value does not change even when the gravimeter station is placed at deep bathymetry. It means that tides greater than this value can affect the data and must be extract from it to avoid masking the effect of the reservoir.

The sensitivity analysis of the reservoir model showed that even at $7 \mathrm{~km}$ deep, the reservoir can be detected by gravimeters placed at $1800 \mathrm{~m}$ with one order of magnitude above the limit of uncertainty. When the oil production is simulated for reservoir at $3 \mathrm{~km}$ deep, the detectability of the 4D gravitational effect starts when the percentage of fluid substitution is between $10 \%$ and $20 \%$.

Further study will go on the direction of generating more complex reservoir models, inserting more realistic geometries and petrophysical parameters. In addition, the feasibility of subsidence can be also studied. Then, all analyzed parameters can be put together to simulate seabottom gravity acquisitions in order to make more robust feasibility 4D gravity studies.

\section{Acknowledgments}

A.D. Arelaro thanks Observatório Nacional and Petrobras S.A. V.C.F. Barbosa was supported from fellowships from: CNPQ (grant 307135/2014-4) and FAPERJ (grant E$26 / 203.091 / 2016)$. V.C. Oliveira Jr was supported by fellowships from CNPQ (grant 308945/2017-4) and FAPERJ (grant E-26/202.729/2018).

\section{References}

AGERSBORG, R., HILLE, L., LIEN, M., et al., 2017. Density Changes and Reservoir Compaction from In-situ Calibrated 4D Gravity and Subsidence Measured at the Sea Floor. In: SPE Annual Technical Conference and Exhibition. Society of Petroleum Engineers.

BLAKELY, Richard J. Potential theory in gravity and magnetic applications. 1995.

PEPPER, T., 1941. The Gulf underwater gravimeter, Geophysics, v. 6, n. 1, pp. 34-44.

ROSTE, T., \& KE, G. (2017). Overburden 4D time shiftsIndicating undrained areas and fault transmissibility in the reservoir. The Leading Edge, 36(5), 423-430.

$\begin{array}{lcr}\text { SCHLUMBERGER, } & \text { Log } & \text { Interpretation } \\ \text { Principles/Applications. } & \text { Schlumberger } & \text { Educational }\end{array}$ Services, 1989.

STENVOLD, T., 2008. Offshore shore gravimetric and subsidence monitoring.

UIEDA, L., OLIVEIRA JR, V. C., BARBOSA, V. C., 2013. Modeling the earth with fatiando a terra. In: Proceedings of the 12th Python in Science Conference (SciPy 2013), pp. 96-103.

VAN CAMP, M., VIRON, O., WATLET, A., et al., 2017. Geophysics From Terrestrial Time-Variable Gravity
Measurements, Reviews of Geophysics, v. 55, n. 4, pp. 938-992. 